\title{
Sistemas de integração lavoura-pecuária na região do Cerrado
}

\author{
Lourival Vilela(1), Geraldo Bueno Martha Junior(2), Manuel Cláudio Motta Macedo(3), Robélio Leandro Marchão(1), \\ Roberto Guimarães Júnior ${ }^{(1)}$, Karina Pulrolnik(1) e Giovana Alcantara Maciel(1)
}

\begin{abstract}
(1)Embrapa Cerrados, Caixa Postal 08223, CEP 73310-970 Planaltina, DF. E-mail: Ivilela@cpac.embrapa.br, robelio.leandro@cpac.embrapa.br, guimaraes@cpac.embrapa.br, karina.pulrolnik@cpac.embrapa.br, giovana.maciel@cpac.embrapa.br (2)Embrapa Estudos Estratégicos e Capacitação, Parque Estação Biológica, Avenida W3 Norte (Final), CEP 70770-901 Brasília, DF. E-mail: geraldo.martha@embrapa.br (3)Embrapa Gado de Corte, Caixa Postal 154, CEP 79002-970 Campo Grande, MS. E-mail: macedo@cnpgc.embrapa.br
\end{abstract}

\begin{abstract}
Resumo - O objetivo deste trabalho foi analisar os benefícios e as perspectivas potenciais de sistemas de integração lavoura-pecuária no processo de intensificação de uso das áreas em exploração com lavoura de grãos e pastagens no Cerrado, e apontar as principais lacunas de informação sobre o sistema. Os principais benefícios da integração lavoura-pecuária são: melhoria das propriedades químicas, físicas e biológicas do solo; redução da ocorrência de doenças, insetos-pragas e plantas daninhas; maior produtividade das plantas e dos animais; e redução de riscos pela diversificação de atividades. No entanto, a adoção do sistema de integração lavoura-pecuária ainda é pequena, provavelmente em virtude da maior complexidade desse sistema. Concentrar esforços nos fatores que limitam a adoção desse sistema no Cerrado parece ser um ponto estratégico para novos estudos. A busca por melhoria na qualidade de cobertura de solo para o sistema plantio direto, por meio de gramíneas forrageiras, pode auxiliar na adoção da integração lavoura-pecuária no Cerrado. A expectativa é de que a adoção de sistemas de integração lavoura-pecuária resulte em melhorias significativas na sustentabilidade socioeconômica e ambiental das propriedades e da sua região de influência.
\end{abstract}

Termos para indexação: agrossilvipastoril, consórcio de culturas com forrageiras, matéria orgânica do solo, plantio direto.

\section{Integrated crop-livestock systems in the Cerrado region}

\begin{abstract}
The objective of this work was to analyze the benefits and the potential prospects of integrated crop-livestock systems in the process of crop and pasture intensification in the Cerrado, and to point out the main information gaps about the system. The main benefits of crop-livestock integration are: improved chemical, physical and biological properties of the soil; reduction of diseases, pests and weed outbreaks occurrence; higher crop and animal productivity; and risk reduction due to diversification of activities. However, the adoption of the crop-livestock system is still low, probably due to the greater complexity of the system. Concentrating efforts on the factors that limit the system's adoption is strategic for new studies. The search for better soil cover for the no tillage system, through forage grasses, can boost the adoption of integrated crop-livestock in the Cerrado. It is expected that the adoption of integrated crop-livestock systems improve the socioeconomic and environmental sustainability of the farm and of its region of influence.
\end{abstract}

Index terms: agrisilvipasture, crop-pasture association, soil organic matter, no tillage.

\section{Introdução}

A demanda crescente por alimentos, bioenergia e produtos florestais, em contraposição à necessidade de redução de desmatamento e mitigação da emissão de gases de efeito estufa, requer soluções que permitam incentivar o desenvolvimento socioeconômico, sem comprometer a sustentabilidade dos recursos naturais. A intensificação do uso da terra em áreas agrícolas e o aumento da eficiência dos sistemas de produção podem contribuir para harmonizar esses interesses. É nesse cenário que a estratégia de integração lavoura-pecuária-floresta, que contempla os sistemas integração lavoura-pecuária, silviagrícolas, silvipastoris e agrossilvipastoris (Balbino et al., 2011), tem sido apontada como alternativa para conciliar esses conflitos de interesse da sociedade. De acordo com Wilkins (2008), os sistemas mistos de produção agrícola são mais sustentáveis do que os sistemas especializados em produção de grãos e fibra.

A integração lavoura-pecuária consiste na implantação de diferentes sistemas produtivos de grãos, fibras, carne, leite, agroenergia, entre outros, na mesma área, em plantio consorciado, sequencial ou

Pesq. agropec. bras., Brasília, v.46, n.10, p.1127-1138, out. 2011 
rotacional (Macedo, 2009). O uso da terra é alternado, no tempo e no espaço, entre lavoura e pecuária. $\mathrm{O}$ interesse, nesse modelo de exploração, apoia-se nos benefícios que podem ser auferidos pelo sinergismo entre pastagens e culturas anuais, como: melhoria das propriedades físicas, químicas e biológicas do solo; quebra de ciclo de doenças e redução de insetos-pragas e de plantas daninhas; redução de riscos econômicos pela diversificação de atividades; e redução de custo na recuperação e na renovação de pastagens em processo de degradação.

O objetivo deste trabalho foi analisar os benefícios e as perspectivas potenciais de sistemas de integração lavoura-pecuária no processo de intensificação de uso das áreas em exploração com lavoura de grãos e pastagens no Cerrado, e apontar as principais lacunas de informação sobre o sistema.

\section{Modalidades de integração lavoura-pecuária}

No Cerrado, vários sistemas de integração lavoura-pecuária são modulados de acordo com o perfil e os objetivos da fazenda. As diferenças nos sistemas podem ser atribuídas às peculiaridades regionais e da propriedade, como condições de clima e de solo, infraestrutura, experiência do produtor e tecnologia disponível.

Três modalidades deintegraçãose destacam: fazendas de pecuária, em que culturas de grãos (arroz, soja, milho e sorgo) são introduzidas em áreas de pastagens para recuperar a produtividade dos pastos; fazendas especializadas em lavouras de grãos, que utilizam gramíneas forrageiras para melhorar a cobertura de solo em sistema plantio direto, e, na entressafra, para uso da forragem na alimentação de bovinos ("safrinha de boi"); e fazendas que, sistematicamente, adotam a rotação de pasto e lavoura para intensificar o uso da terra e se beneficiar do sinergismo entre as duas atividades. Esses sistemas podem ser praticados por parcerias entre lavoureiros e pecuaristas.

Nessas parcerias, além de se aproveitar a forragem produzida no consórcio, os resíduos da colheita de grãos ("bandinha e casquinha de soja", "piolho de algodão", palhada de milho, entre outros) são utilizados como suplementos para a alimentação animal, no período de seca, em pastejo ou em confinamento. De acordo com Moraes et al. (2007), no Sul do Brasil, introduzir a forrageira apenas como cobertura de solo para o plantio direto não é o mais rentável, pois a produção animal aumenta a rentabilidade no sistema soja verão-pastagem outono-inverno.

Por ocasionar competição entre a forrageira e as culturas, o plantio consorciado de capim com cultura de grãos nem sempre maximiza a produtividade dos componentes. Sem a adoção da tecnologia correta, mais adequada para as condições da área, podem ocorrer perdas expressivas de produtividade da lavoura de grãos (Kluthcouski \& Aidar, 2003) ou redução na biomassa de forragem (Jakelaitis et al., 2005), o que compromete a produção animal na entressafra.

\section{Consórcio de culturas anuais com forrageiras}

$\mathrm{Na}$ integração lavoura-pecuária, o consórcio de culturas de grãos com forrageiras é adotado para antecipar o estabelecimento das pastagens e melhorar a cobertura de solo para o plantio direto. As culturas de milho e de sorgo, em virtude da maior capacidade de competição com as gramíneas forrageiras Urochloa spp. (Syn. Brachiaria spp.) e Panicum maximum, na fase inicial de estabelecimento, têm sido as mais adotadas nos consórcios cultura anual-pasto. Alternativas para minimizar essa competição são: plantio defasado (sobressemeadura), uso de subdoses de herbicidas para reduzir a competição da forrageira com a cultura de grãos e arranjo de plantas (Portes et al., 2000; Cobucci \& Portela, 2003; Kluthcouski \& Aidar, 2003; Jakelaitis et al., 2004; Freitas et al., 2005).

A soja tem sido incluída na rotação com outras culturas de grãos (milho e sorgo) e com forrageiras, na integração lavoura-pecuária. As principais rotações utilizadas para implantação da pastagem ou das forrageiras como planta de cobertura são: soja-safrinha de milho consorciado com capim (quando as condições climáticas são favoráveis) ou apenas uma safra anual; soja-safrinha de capim; e soja consorciada com forrageiras em semeadura simultânea ou defasada, em relação à da cultura de grãos.

O consórcio do capim com a soja, embora possa ser realizado, é operacionalmente complicado e, em determinadas situações, pode prejudicar a produtividade de grãos ou de forragem (Vilela et al., 2006). Quando em consórcio, o uso de subdoses de herbicidas tem minimizado a redução da produtividade de grãos e garantido o estabelecimento das forrageiras.

O consórcio soja-pasto tem sido avaliado, e os resultados obtidos ainda são inconsistentes. De acordo com Kluthcouski \& Aidar (2003), as reduções na 
produtividade de grãos de soja em consórcio com Urochloa brizantha cultivar Marandu oscilaram entre 1 e 74\%, em comparação ao cultivo solteiro. Essa variação indica que há possibilidade de consórcio de soja com gramíneas forrageiras. As maiores produtividades foram obtidas quando o capim-marandu foi controlado com subdoses de herbicida haloxyfop-methyl.

A competição da gramínea foi mínima quando a soja foi consorciada com forrageiras de pequeno porte e de crescimento inicial lento, como o capim-massai (Machado \& Ceccon, 2010). Em razão dos altos custos de produção de soja, até mesmo pequenas reduções na produtividade podem comprometer a sustentabilidade econômica do produtor.

A adoção de soja transgênica, resistente ao herbicida glifosato, é uma alternativa que apresenta potencial para aumentar o sucesso de plantio consorciado desta cultura com gramíneas forrageiras tropicais.

Apesar de estudos sobre o consórcio de capim com soja terem mostrado o potencial dessa prática (Kluthcouski \& Aidar, 2003; Silva et al., 2004, 2006), a inconsistência dos resultados obtidos em diferentes regiões é indicativo de que são necessárias mais pesquisas para sua recomendação. Também há necessidade de mais estudos para ajustar o manejo de herbicida, reduzir a competição entre a soja e o capim, e facilitar a colheita da soja.

A semeadura defasada da forrageira, em relação ao plantio da cultura de grãos, pode promover a redução da competição entre os componentes do consórcio. O plantio da forrageira de 10 a 20 dias após a emergência da soja eliminou a competição da gramínea, e a produtividade da cultura não foi comprometida (Silva et al., 2005; Machado \& Ceccon, 2010). No entanto, o plantio defasado, de um período superior a três semanas, afeta negativamente o desenvolvimento do capim, com prejuízos à fase de pastagem da integração lavoura-pecuária.

Em regiões com condições favoráveis de clima, para minimizar o risco de redução de produção da soja na integração lavoura-pecuária, o plantio direto das forrageiras pode ser realizado após a colheita da soja (Machado \& Assis, 2010). Os plantios de soja no início das chuvas, com cultivares de ciclo precoce e médio, permitem a semeadura da forrageira em sucessão à soja. O capim pode ser semeado "solteiro" ou em consórcio com cultura de grãos (safrinha de sorgo e de milho) ou com forrageiras anuais (milheto e sorgo forrageiro).

\section{Produção animal}

As fazendas que adotam a rotação lavoura-pasto como estratégia de produção agrícola podem se beneficiar da melhor estabilidade de produção de forragem para alimentar o rebanho durante o ano todo. No período das chuvas, as pastagens são mais produtivas, em virtude da melhoria da fertilidade do solo pelas lavouras. No período da seca, além da palhada e dos subprodutos de colheita, os pastos recém-estabelecidos permanecem verdes e com qualidade e quantidade para conferir ganhos de peso positivos ao invés de perda de peso, comum neste período do ano, na maioria das fazendas da região do Cerrado.

Durante a época seca, Alvarenga et al. (2007) observaram, em pastagem de $P$. maximum cultivar Tanzânia, estabelecida em consórcio com milho, ganhos de peso em novilhos de recria entre 700 e $900 \mathrm{~g}$ por animal por dia. Essa variação de $28 \%$ no ganho de peso foi resultante dos grupos genéticos avaliados. Os maiores ganhos foram dos animais de cruzamento industrial (Nelore x Red Angus) e os menores, dos animais mestiços (Nelore x Girolando).

Animais com potencial genético limitado contribuem para a menor produtividade do sistema. Barcellos et al. (1999) demonstraram a importância de associar genética animal ao manejo do pasto e à renovação de pastagens degradadas. Durante 15 meses, o ganho de peso de animais cruzados (Nelore x Blond D'Aquitaine), de maior potencial de produção, superou o ganho de peso de animais Nelore em 8,8\% (161 kg x $148 \mathrm{~kg}$ ), quando o pasto estava degradado. Em pastagens renovadas por meio de adubação ou de cultivo de milho e arroz e manejadas adequadamente, o ganho de peso dos animais cruzados superou o dos Nelores em $24,9 \%$ (266 kg x $213 \mathrm{~kg})$. As produtividades no pasto degradado e no pasto renovado, com manejo do pastejo adequado, foram de 51 e $310,5 \mathrm{~kg}$ por hectare por ano equivalente de carcaça, respectivamente. $\mathrm{O}$ maior potencial produtivo obtido pelo cruzamento de raças ou pelo melhoramento genético/seleção do rebanho sempre deverá estar associado à melhoria da qualidade alimentar ofertada aos animais (Martha Junior et al., 2007).

\section{Impactos da integração lavoura-pecuária}

A substituição de sistemas especializados de produção de grãos, fibras, carne e leite por sistemas 
de integração lavoura-pecuária, mais complexos, gera impactos no solo, no ambiente, no desempenho econômico potencial e no manejo global da propriedade. Esses impactos, que podem ser positivos ou negativos, dependendo da situação, precisam ser bem compreendidos.

Entre os impactos negativos, o mais frequentemente citado na literatura e relatado por produtores, é o resultante do pisoteio animal. A compactação depende, principalmente, do tipo de solo, do seu teor de umidade, da taxa de lotação animal e da massa de forragem (Moraes et al., 2007), da espécie forrageira utilizada no sistema (Marchão et al., 2007) e do vigor da planta forrageira (Corsi et al., 2001). A compactação do solo pelo pisoteio animal, agravada pela remoção da vegetação, via desfolha, pode diminuir a taxa de infiltração de água, aumentar a erosão superficial do solo e reduzir o crescimento das plantas (Greenwood \& McKenzie, 2001). Contudo, os impactos negativos do pisoteio animal no solo limitam-se às camadas superficiais e podem ser temporários e reversíveis (Corsi et al., 2001; Cassol, 2003; Lanzanova et al., 2007).

Na região do Cerrado, o impacto do pisoteio animal sobre as propriedades físicas, químicas e biológicas do solo tem recebido pouca atenção da pesquisa. A compactação superficial do solo e a redução na taxa de infiltração da água foram observadas em pastagens em degradação (Macedo, 1997), o que é justificado pelo baixo vigor da planta forrageira nessas situações (Corsi et al., 2001). No entanto, mais estudos são necessários para estabelecer as relações mais indicadas entre a utilização das forrageiras e a qualidade do solo, em sistema de integração lavoura-pecuária.

Em experimento de longa duração no Cerrado, Marchão et al. (2007) demonstraram que a compactação de solo em sistemas de integração lavoura-pecuária, após 13 anos, não atingiu valores limitantes. Estes autores observaram que a compactação de solo foi maior nas áreas com gramíneas de hábito de crescimento cespitoso, principalmente do gênero Panicum. O crescimento cespitoso das plantas distribui a pressão imposta pelo pisoteio animal de maneira menos efetiva, em comparação a plantas que formam relvado.

A melhoria das propriedades físicas, químicas e biológicas dos solos é uma questão chave no desenvolvimento de sistemas de produção agrícolas mais sustentáveis. De acordo comFranzluebbers (2007), os sistemas mais diversificados, como a integração lavoura-pecuária, são importantes para repor e manter a matéria orgânica do solo (MOS) e proporcionar solos bem estruturados, o que favorece: maior taxa de infiltração de água das chuvas e, subsequentemente, maior disponibilidade para os cultivos; redução do escorrimento superficial, para evitar erosões e poluição dos corpos d'água; e penetração das raízes no perfil do solo, o que aumenta o volume de solo explorado pelo sistema radicular dos cultivos e, consequentemente, a eficiência de uso de água e nutrientes.

A diversificação das espécies vegetais em sistemas de integração lavoura-pecuária promove maior diversidade de espécies de fungos micorrízicos arbusculares (Miranda et al., 2005) e de grupos da macrofauna invertebrada do solo (Silva et al., 2006; Marchão et al., 2009). A macrofauna invertebrada do solo desempenha papel chave no funcionamento do ecossistema, por participar em diferentes níveis tróficos da cadeia alimentar no solo. Esses invertebrados do solo alteram as populações e a atividade de microrganismos responsáveis pelos processos de mineralização e humificação da MOS, além de alterarem a disponibilidade de nutrientes assimiláveis pelas plantas (Decaëns et al., 2003). Os fungos micorrízicos arbusculares, por meio da micorriza arbuscular, podem aumentar a absorção de nutrientes do solo, como o fósforo, deficiente na maioria dos solos do Cerrado.

Para mitigação das mudanças climáticas, um dos desafios é conservar os estoques de carbono dos ecossistemas e remover carbono da atmosfera, incorporando-o aos estoques existentes (Guo \& Gifford, 2002), o que ocorre em sistemas de integração lavoura-pecuária com manejo eficiente. As pastagens bem manejadas, de modo geral, têm potencial para aumentar o teor de carbono do solo.

Guo \& Gifford (2002), ao utilizar o procedimento estatístico de meta análise para avaliar o impacto da mudança do uso da terra nos estoques de carbono no solo (537 observações de 74 publicações do Brasil e de outros 15 países), verificaram que a substituição de florestas nativas ou de lavoura por pastagem aumentou o teor de carbono do solo de 8 a 19\%. A substituição das pastagens por floresta plantada ou por lavouras de grãos resultou em decréscimos de 10 e 59\%, respectivamente.

Para conservar o solo produtivo por um longo período, é necessário desenvolver sistemas de cultivo que permitam manter ou melhorar a sua estrutura. 
Segundo Lynch \& Bragg (1985), o método mais prático de manipular a estrutura do solo é a inclusão de espécies forrageiras nos sistemas de produção. Lal (1991) relata que a rotação de culturas anuais e pastagens é uma das melhores alternativas para obter manejo sustentável do solo e da água nos trópicos.

Para regenerar a estrutura do solo, é necessário promover o aumento da sua agregação, o que pode ser obtido pelo aumento da MOS (Castro Filho et al., 1991). Em solos intemperizados, como os do Cerrado, a capacidade de troca catiônica (CTC) depende, em essência, da MOS. De acordo com Sousa \& Lobato (2004), 75 a 93\% da CTC dos solos de Cerrado se originam da MOS.

As pastagens bem manejadas, em contraste com os cultivos anuais em plantio convencional e em plantio direto, têm a capacidade de aumentar o teor de MOS acima dos teores originais observados com vegetação nativa (Studdert et al., 1997; Sousa et al., 2007, 2010). Durante 13 anos de cultivo de soja, o teor de MOS apresentou redução de $24,4 \%$, quando comparado com o valor original $(3,6 \%)$. Porém, a inclusão de $U$. humidicola, manejada sob cortes, aumentou continuamente o teor de MOS durante os nove anos de avaliação. No período em que a área estava com $U$. humidicola, a taxa de aumento no teor de MOS foi estimada em 1,67 $\mathrm{Mg} \mathrm{ha}^{-1}$ por ano. Com o retorno da lavoura de grãos (rotação soja-milho) no sistema, o teor de MOS passou a decrescer, mas manteve diferença em torno de $30 \%$ a mais, em comparação ao sistema de rotação contínua com cultivos anuais até o último ano (Sousa et al., 2007, 2010).

A integração lavoura-pecuária, em sistema plantio direto, pode reduzir a variação no teor de MOS que ocorre com a mudança de componentes, aumentando com a pastagem e reduzindo com a lavoura de grãos. No Uruguai, em experimento de longa duração de rotação lavoura-pastagem, o mais antigo da América Latina, García-Préchac et al. (2004) relataram que a adoção de plantio direto na rotação de lavoura-pasto, após 27 anos em plantio convencional, minimizou a flutuação no teor de MOS e manteve ou aumentou o seu teor. Na fase de plantio convencional, de 1964 a 1990, o declínio da MOS, na camada de 0 a $20 \mathrm{~cm}$, foi de $540 \mathrm{~kg} \mathrm{ha}^{-1}$ por ano, no sistema de lavoura contínua. Entretanto, na rotação lavoura-pastagem, a perda de MOS foi de apenas $80 \mathrm{~kg} \mathrm{ha}^{-1}$ por ano. A maior parte da MOS perdida durante o período de lavoura em plantio convencional era recuperada durante o ciclo de pastagem.

Ao avaliar o efeito de pastagem no aumento da MOS, em três experimentos de longa duração (Tabela 1), Salton (2005) observou que o estoque de carbono foi maior na pastagem permanente de $U$. decumbens, intermediário na rotação soja-pasto e inferior na lavoura em plantio direto. Entre os locais, a variação no estoque de carbono do solo também foi significativa $(\mathrm{p}<0,01)$, o que reflete as variações edafoclimáticas. De modo geral, o uso de pastagens possibilitou manter ou superar a quantidade de carbono observada na vegetação nativa de referência.

Sousa et al. (2007) avaliaram a eficiência de uso de fósforo após $U$. humidicola. A produtividade do primeiro cultivo com soja, após um ciclo de nove anos de pastagem, foi superior ao sistema exclusivo de culturas anuais (décimo terceiro cultivo de soja) para um mesmo teor de $\mathrm{P}$ no solo, o que evidencia a maior eficiência do uso deste nutriente quando a pastagem foi inserida na rotação. É provável que o menor nível crítico de fósforo na rotação pastagem-soja seja resultante de: reciclagem mais eficiente de $\mathrm{P}$ no sistema; acréscimos na taxa de mineralização da MOS, acumulada durante o período da pastagem; ou bloqueio dos sítios de adsorção de fósforo pelo maior acúmulo de matéria orgânica, o que reduz a fixação desse elemento (Fox \& Searle, 1978). Esses resultados são indicativos da melhor eficiência de uso de fósforo pelas plantas, em sistemas de rotação cultura anual-pastagem do que em culturas anuais.

Em outro estudo realizado na Embrapa Cerrados, Martha Junior et al. (2010) avaliaram a eficiência de uso de fertilizantes na integração lavoura-pecuária.

Tabela 1. Efeito de sistemas de manejo nos estoques de carbono orgânico total $\left(\mathrm{Mg} \mathrm{ha}^{-1}\right)$, na camada de 0 a $20 \mathrm{~cm}$ de profundidade, em experimentos de longa duração, em Mato Grosso do Sul.

\begin{tabular}{lcccc}
\hline Sistema & \multicolumn{3}{c}{ Local } & Média $^{(1)}$ \\
\cline { 2 - 4 } & Campo Grande & Maracaju & Dourados \\
\hline Lavoura em plantio direto & 47,39 & 56,60 & 42,59 & 48,86 \\
Rotação soja-pasto & 50,50 & 61,40 & 48,04 & 53,31 \\
Pastagem permanente ${ }^{(2)}$ & 53,50 & 65,80 & 50,10 & 56,47 \\
Vegetação nativa & 53,98 & 68,70 & 44,49 & 55,72 \\
\hline Média & 51,34 & 63,13 & 46,30 & 53,59 \\
\hline${ }^{(1)}$ Médias de sistemas e locais diferem significativamente entre si, a DMS \\
5\% igual a 3,54. (2) Urochloa decumbens. Adaptado de Salton (2005).
\end{tabular}

Pesq. agropec. bras., Brasília, v.46, n.10, p.1127-1138, out. 2011 
A primeira fase do experimento, com duração de quatro anos, consistiu em diferentes estratégias de adubação para o restabelecimento da produção de forragem de pastagens em degradação de $U$. decumbens cultivar Basilisk. Além de um tratamento testemunha, sem adubação, foram testadas doses anuais de fósforo, de 20 e $40 \mathrm{~kg} \mathrm{ha}^{-1}$ de $\mathrm{P}_{2} \mathrm{O}_{5}$, acompanhadas de adubações anuais de $60 \mathrm{~kg} \mathrm{ha}^{-1}$ de $\mathrm{N}$ (primeiros dois anos) ou $90 \mathrm{~kg} \mathrm{ha}^{-1}$ de $\mathrm{N}$ (terceiro e quarto ano) e de $60 \mathrm{~kg} \mathrm{ha}^{-1}$ de $\mathrm{K}_{2} \mathrm{O}$. Após essa fase de pecuária, cultivou-se a soja, em plantio direto, por dois anos consecutivos, o que totalizou seis anos de avaliação. No plantio de soja, três doses da fórmula N-P-K (0-20-20) + micronutrientes foram avaliadas: 0,50 e $100 \mathrm{~kg} \mathrm{ha}^{-1}$ de $\mathrm{P}_{2} \mathrm{O}_{5}$ e $\mathrm{K}_{2} \mathrm{O}$.

No primeiro ano de cultivo, a produtividade de soja na dose de $500 \mathrm{~kg} \mathrm{ha}^{-1}$ de fórmula foi de 3,4 $\mathrm{Mg} \mathrm{ha}^{-1}$, na área da pastagem que não recebeu adubações anuais de NPK. Quando foram feitas adubações na pastagem, foi possível atingir esse patamar de produtividade de soja com menos fertilizante ou obter ganhos de até $18 \%$, com produção superior a 4,0 Mg ha' ${ }^{-1}$, com $100 \mathrm{~kg} \mathrm{ha}^{-1}$ de $\mathrm{P}_{2} \mathrm{O}_{5}$ e $\mathrm{K}_{2} \mathrm{O}$. No segundo ano de cultivo de soja em sucessão à pastagem, esse efeito de "economia no uso de fertilizantes" foi substancialmente reduzido. Ao se considerar as doses de adubação da soja, de 0,50 e $100 \mathrm{~kg} \mathrm{ha}^{-1} \mathrm{de}_{2} \mathrm{O}_{5}$ e $\mathrm{K}_{2} \mathrm{O}$, as produtividades médias do segundo cultivo de soja, em comparação ao primeiro, foram de 58,84 e $92 \%$, respectivamente.

Em experimento de longa duração, na Embrapa Cerrados, observou-se benefício da pastagem na produtividade de grãos de soja (Tabela 2). A produtividade de soja após um ciclo de três anos de pasto de $U$. brizantha cultivar Marandu foi de 17\% (510 kg ha-1), superior ao obtido no sistema de lavoura contínua. Cabe ressaltar que essa maior produtividade de grãos foi obtida em área que recebeu menores quantidades de fertilizantes, em média $45 \%$ a menos, durante os 17 anos de cultivo. A maior eficiência no uso dos nutrientes do solo pelas culturas de grãos na integração lavoura-pecuária, em comparação ao cultivo solteiro, resulta em economia de fertilizantes e, consequentemente, na redução dos custos de produção. Contudo, esses benefícios nem sempre são facilmente obtidos a curto prazo.

O potencial produtivo do pasto de capim-marandu ainda era alto antes do plantio de soja (Tabela 2). Em 134 dias de pastejo, no período das chuvas, o ganho de peso foi de $683 \mathrm{~kg} \mathrm{ha}^{-1}$ de peso vivo. A amplitude de ganho de peso vivo em pasto de primeiro ano, em sistemas de integração lavoura-pecuária, tem variado de $600 \mathrm{a}$ $1.200 \mathrm{~kg} \mathrm{ha}^{-1}$ por ano e de 270 a $450 \mathrm{~kg} \mathrm{ha}^{-1}$ por ano, em função da amplitude nas condições edafoclimáticas e do manejo nos diferentes locais, respectivamente (Martha Junior et al., 2006).

$\mathrm{Na}$ Tabela 3, são descritos os resultados de ganho de peso animal, em experimento de longa duração da Embrapa Gado de Corte, onde estão sendo testados diferentes sistemas tradicionais e de integração lavoura-pecuária (Macedo, 2009). Sistemas tradicionais de pastagem (PC), embora apresentem resposta à adubação de manutenção, não apresentam a mesma eficiência econômica, quando comparados aos sistemas de rotação lavoura-pasto (L4-P4 e L1-P3). Nestes sistemas, a venda de grãos das lavouras é acrescentada às produções animais. Os efeitos indiretos, como melhoria das propriedades do solo, apesar de não computados, também são vantajosos para os sistemas de integração lavoura-pecuária.

$\mathrm{O}$ aumento na produtividade das lavouras e dos animais, em sistemas de integração lavoura-pecuária, é resultante da interação de vários fatores, muitas vezes, de difícil separação. Além da melhoria das

Tabela 2. Produtividade de soja em dois sistemas de cultivo - lavoura contínua (LC) e rotação lavoura-pasto de Urochloa brizantha cultivar Marandu-lavoura (LPL) - submetidos a dois sistemas de plantio em Latossolo Vermelho, de textura argilosa, em Planaltina, DF.

\begin{tabular}{|c|c|c|c|c|c|}
\hline \multirow{2}{*}{$\begin{array}{l}\text { Rotação } \\
2004 \text { a } 2006\end{array}$} & \multirow{2}{*}{$\begin{array}{c}\mathrm{N}-\mathrm{P}_{2} \mathrm{O}_{5}-\mathrm{K}_{2} \mathrm{O}^{(1)} \\
1991 \text { a } 2007\end{array}$} & \multirow{2}{*}{$\begin{array}{l}\text { Lavoura }^{(2)} \\
\text { 2007/2008 }\end{array}$} & \multicolumn{2}{|c|}{ Sistema de plantio } & \multirow[t]{2}{*}{ Média ${ }^{(3)}$} \\
\hline & & & Convencional & Direto & \\
\hline & $\left(\mathrm{kg} \mathrm{ha}^{-1}\right)$ & & ------------- & --- $(\mathrm{kg}$ & ----------. \\
\hline Soja-sorgo-soja (LC) & $308-1.487-1.390$ & Soja & 3.078 & 3.044 & $3.061 \mathrm{a}$ \\
\hline U. brizantha (LPL) & 85-853-813 & Soja & 3.540 & 3.603 & $3.571 \mathrm{a}$ \\
\hline Média $^{(3)}$ & & & $3.309 \mathrm{a}$ & $3.323 \mathrm{a}$ & \\
\hline
\end{tabular}

${ }^{(1)}$ Total de corretivos e nutrientes aplicados em 17 anos de cultivo. ${ }^{(2)} \mathrm{Na}$ safra de 2007/2008, a adubação de plantio da soja foi de $485 \mathrm{~kg} \mathrm{~h}^{-1}$ da fórmula N-P-K (0-20-20) + S + micronutrientes. ${ }^{(3)}$ Médias seguidas de letras iguais não diferem entre si pelo teste de Tukey, a 5\% de probabilidade. Adaptado de Vilela et al. (2008). 
propriedades físicas, químicas e biológicas do solo, a quebra de ciclos bióticos (pragas e doenças) contribui para aumentar a produtividade do sistema (Costa \& Rava, 2003; Vilela et al., 2003).

O milho safrinha consorciado com $U$. ruziziensis pode desinfestar mais intensivamente solos com o fungo do mofo-branco (Sclerotinia sclerotiorum), em comparação ao milho safrinha solteiro (Görgen et al., 2010). Costa \& Rava (2003), ao avaliar doenças de solo, em sistemas de rotação lavoura-pastagem, demonstraram o efeito positivo da palhada de $U$. ruziziensis e de $U$. brizantha cultivar Marandu no controle de Fusarium solani, Rhizoctonia solani e $S$. sclerotiorum.

No caso das pragas de solo, o aumento de população de Pratylenchus brachyurus em lavouras de soja e algodão, sobretudo em Mato Grosso, tem gerado inquietação entre os produtores. Para reduzir a população desses nematoides, tem sido adotada a rotação de culturas anuais com pastos. Entretanto, Inomoto et al. (2007) relataram que os principais capins (U. brizantha cultivar Marandu, Panicum maximum cultivares Tanzânia e Mombaça, e U. ruziziensis) utilizados em sistemas de integração lavoura-pecuária favorecem a multiplicação de $P$. brachyurus.

A redução da população de plantas daninhas é outro benefício dos sistemas mistos relatado na literatura nacional e estrangeira (Cobucci \& Portela, 2003; Severino et al., 2006; Ikeda et al., 2007). Em estudo realizado em experimento de longa

Tabela 3. Produção animal em pastagem degradada e recuperada e em pastagem de sistemas de integração lavoura-pecuária em Latossolo de Cerrado, em Campo Grande, MS.

\begin{tabular}{lc}
\hline Sistema & $\begin{array}{c}\text { Ganho de peso } \\
\left(\mathrm{kg} \mathrm{ha}^{-1}\right)\end{array}$ \\
\hline Pastagem degradada $^{(2)}$ & $141 \pm 54$ \\
Pastagem recuperada sem adubação de manutenção & $328 \pm 96$ \\
Pastagem recuperada com adubação de manutenção & $381 \pm 84$ \\
Rotação de 4 anos de lavoura seguidos de 4 anos de & $495 \pm 104$ \\
pastagem (L4-P4) & \\
$\begin{array}{l}\text { Rotação de 1 ano de lavoura seguido de 3 anos de } \\
\text { pastagem (L1-P3) }\end{array}$ & $518 \pm 174$ \\
\hline
\end{tabular}

${ }^{(1)}$ Média de 12 ciclos de pastejo para pastagens contínuas e de seis ciclos para pastagens da rotação lavoura-pasto. ${ }^{(2)}$ Nas pastagens contínuas, a espécie forrageira é a Urochloa decumbens. ${ }^{(3)}$ Adubações anuais com $50 \mathrm{~kg} \mathrm{ha}^{-1}$ de $\mathrm{N}$ e $40 \mathrm{~kg} \mathrm{ha}^{-1}$ de $\mathrm{P}_{2} \mathrm{O}_{5}$ e de $\mathrm{K}_{2} \mathrm{O}$. ( ${ }^{(4)}$ Pastagem de Panicum maximum cultivar Tanzânia. ${ }^{(5)}$ Pastagem de $U$. brizantha cultivar Marandu. Adaptado de Macedo (2009). duração na Embrapa Cerrados, Ikeda et al. (2007) constataram reduções significativas nos bancos de sementes de plantas daninhas em sistema de rotação lavoura-pasto, em comparação ao sistema de lavoura continua, principalmente quando se adotou o plantio direto (Tabela 4). A redução do uso de agroquímicos, em virtude da quebra dos ciclos de pragas, doenças e plantas daninhas, é outro benefício ao meio ambiente de sistemas como a integração lavoura-pecuária.

Em relação aos benefícios dos sistemas de integração lavoura-pecuária, o exemplo da Fazenda Santa Terezinha, em Uberlândia, MG, evidencia o potencial desses sistemas em fazendas comerciais (Tabela 5). Essa propriedade desenvolvia atividade de cria e, em 1983, apresentava uma área de 1.014 ha de pastagem, com rebanho de 1.094 cabeças (taxa de lotação de 1,1 cabeças por hectare). A partir de 1985, a propriedade passou a destinar áreas de pastagens para a produção de grãos até atingir, em 1996, a totalidade da área com um ou mais ciclos de lavoura. Em 1996, a área destinada a pastagens representava $36 \%$ da área total da fazenda, e o rebanho era de 1.200 cabeças, o que representa taxa de lotação três vezes superior à inicial. A maior taxa de lotação foi reflexo da recuperação da fertilidade do solo e da utilização de gramíneas com maior potencial de produção de forragem. É importante ressaltar que a redução na taxa de lotação, em 2003, não foi decorrente da perda da capacidade de suporte das pastagens, mas da reorientação de metas e objetivos do sistema de produção (Vilela et al., 2008).

Tabela 4. Número de sementes por metro quadrado no solo, em áreas de experimento de cultivo lavoura-pastagem, na profundidade de $0-20 \mathrm{~cm}$, em Planaltina, $\mathrm{DF}^{(1)}$.

\begin{tabular}{lcc}
\hline \multirow{2}{*}{ Sistema } & \multicolumn{2}{c}{ Número de sementes } \\
\cline { 2 - 3 } & Adubação de manutenção & Adubação corretiva gradual \\
\hline LC & $23.654 \mathrm{bA}$ & $21.839 \mathrm{aA}$ \\
LD & $10.468 \mathrm{cA}$ & $9.744 \mathrm{bA}$ \\
LPLC & $45.747 \mathrm{aA}$ & $24.400 \mathrm{aB}$ \\
LPLD & $2.815 \mathrm{deA}$ & $2.882 \mathrm{dA}$ \\
PLPC & $2.389 \mathrm{eB}$ & $5.115 \mathrm{cA}$ \\
PLPD & $5.167 \mathrm{dA}$ & $4.472 \mathrm{cA}$ \\
PC & - & $1.322 \mathrm{e}$ \\
\hline
\end{tabular}

${ }^{(1)}$ Médias seguidas de letras iguais, minúsculas na coluna e maiúsculas na linha, não diferem entre si pelo teste de Wilcoxon, a $5 \%$ de probabilidade. Para cada comparação, utilizou-se DMS diferente. L, lavoura contínua; LPL, lavoura-pastagem-lavoura; PLP, pastagem-lavoura-pastagem; P, pastagem contínua; $\mathrm{C}$, preparo convencional do solo; $\mathrm{D}$, semeadura direta; -, área não avaliada. Em cada área, foram coletadas oito amostras compostas por quatro subamostras de 7,3 cm de diâmetro. Adaptado de Ikeda et al. (2007). 
Nessa fazenda, a percentagem de agregados estáveis em água com diâmetros maiores do que $2,0 \mathrm{~mm}$ foi de $89 \%$, nas áreas de pastagem após cultura. Nas áreas cultivadas com soja por quatro anos, esse valor foi de $46 \%$. Os teores de MOS nas áreas de pastagens plantadas após a soja (um e quatro cultivos) aumentaram, em média, 30\% (Ayarza et al., 1999).

$\mathrm{O}$ efeito das pastagens foi evidente na produtividade das culturas anuais. A produtividade de grãos de soja correlacionou-se significativamente com a idade da pastagem que antecedia as culturas anuais na rotação. Para cada ano de pastagem, a produtividade de grãos aumentou em $127 \mathrm{~kg} \mathrm{ha}^{-1}$. Esse valor, embora expressivo, foi inferior aos $170 \mathrm{~kg} \mathrm{ha}^{-1}$, para cada ano de pastagem, estimado com base nos resultados obtidos (Tabela 2). Entre outros fatores, essas respostas diferenciadas podem ser atribuídas às diferenças no potencial de produtividade agrícola dos solos (Neossolo Quartzarênico vs. Latossolo Vermelho, de textura argilosa) e das cultivares de soja utilizadas (Spain et al., 1996; Ayarza et al., 1999).

Os benefícios econômicos da integração lavoura-pecuária, pela ótica da iniciativa privada, centram na possibilidade de aumentar a oferta com custos de produção unitários menores. Esses custos menores refletem a ampliação do potencial de produção do sistema (por exemplo, em razão de aumentos na MOS e da maior capacidade de armazenamento de água e de nutrientes) para uso de insumos, maior eficiência no uso de fertilizantes e menor demanda por agroquímicos.

Tabela 5. Evolução da rotação de lavoura-pastagem e da capacidade de suporte das pastagens na fazenda Santa Terezinha, em Uberlândia, MG, sob Neossolo Quartzarênico.

\begin{tabular}{cccccc}
\hline Ano & $\begin{array}{c}\text { Proporção de área dos componentes } \\
(\%)\end{array}$ & Rebanho & Taxa de lotação \\
& \multicolumn{5}{c}{${ }^{(2)}$} \\
& $\begin{array}{c}\text { Pasto } \\
\text { degradado }\end{array}$ & $\begin{array}{c}\text { Lavoura } \\
\text { de grãos }\end{array}$ & $\begin{array}{c}\text { Pasto } \\
\text { recuperado }\end{array}$ & (cabeça) & (cabeça por hectare) \\
\hline 1983 & $100^{(1)}$ & 0 & 0 & 1.094 & 1,1 \\
1988 & 29 & 42 & 29 & 821 & 1,4 \\
1992 & 0 & 59 & 41 & 1.150 & 2,8 \\
1996 & 0 & 64 & 36 & 1.200 & 3,2 \\
2003 & 0 & 30 & 70 & 1.800 & 2,6 \\
\hline
\end{tabular}

(1)Área inicial de pastagem igual a 1.000 ha. ${ }^{(2)}$ Taxa de lotação estimada para o período de chuvas. Durante a estação da seca, os animais também ocuparam as áreas de lavoura para aproveitamento das restevas de milho e soja. Adaptado de Vilela et al. (2008).
Lazzarotto et al. (2009), no Paraná, verificaram que as rendas líquidas na integração lavoura-pecuária superaram aquelas com grãos e pecuária de corte em $\mathrm{R} \$ 36,7$ e $\mathrm{R} \$ 51,1$, respectivamente. Estes autores também observaram que a chance de o empreendimento apresentar resultado negativo foi de $52 \%$ para lavouras de grãos, de $39 \%$ para pecuária de corte e de $26 \%$ para integração lavoura-pecuária.

\section{Impactos ambientais}

Elevadas produtividades das lavouras e das pastagens aumentam a demanda por insumos modernos. A integração lavoura-pecuária pode promover aumento na eficiência de uso desses insumos, o que resultaria em menor uso de insumos para uma dada meta de produção.

Nos Estados Unidos, a pecuária tem sido responsabilizada pela emissão de $21 \%$ de metano de todas as atividades agrícolas do país (United States Environmental Protection Agency, 1993). Segundo Lima (2002), no Brasil, a maior parte das emissões de metano tem origem em áreas de pastagens extensivas. Provavelmente, a maioria destas pastagens está em processo de degradação, e o menor desempenho animal implica maior emissão de metano por unidade de produto. Portanto, o aumento na produtividade animal é uma estratégia importante para a mitigação da emissão de metano. Deramus et al. (2003) verificaram que menos metano foi produzido por unidade de ganho de peso com a adoção de melhores práticas de manejo associadas ao pastejo intensivo, em pastagens adubadas com nitrogênio, fósforo e potássio. A redução na emissão anual de metano foi de $22 \%$.

Para mitigar a emissão dos gases de efeito estufa, de acordo com Feigl et al. (2001), é imprescindível melhorar o manejo das pastagens implantadas. Assim, se a recuperação das pastagens for feita consoante às boas práticas de manejo, por adubação direta ou integração lavoura-pecuária, essa ação poderia desempenhar papel fundamental na melhoria da eficiência dos processos relacionados à mitigação da emissão desses gases.

A cobertura do solo proporcionada pelas pastagens é normalmente muito eficiente no controle do escorrimento superficial de água e, consequentemente, da erosão. Em comparação aos principais cultivos do Cerrado, as pastagens são as mais eficientes no controle de perda de água e solo (Dedecek et al., 
1986). Em razão da estreita relação que existe entre escorrimento superficial e erosão do solo, qualquer prática que aumente a taxa de infiltração e a cobertura de solo reduz a perda de sedimentos (Thurow, 1991). Portanto, a degradação de pastagem é um processo com alto potencial para causar erosão e assoreamento de nascentes, rios, represas e lagos.

Das oito grandes bacias hidrográficas brasileiras, seis têm suas nascentes em áreas de Cerrado (Lima \& Silva, 2008). O Bioma Cerrado é responsável por $71 \%$ da vazão gerada na Bacia Araguaia-Tocantins, 94\% na Bacia do São Francisco e $71 \%$ na Bacia Paraná-Paraguai. Ao se considerar a importância desse bioma para a expansão do setor agrícola e para a manutenção da oferta hídrica nacional, é importante avaliar quais são os impactos da degradação de mais de $50 \%$ dos 54 milhões de hectares de pastagens do Cerrado no ciclo hidrológico dessas bacias.

Com o sistema de integração lavoura-pecuária, a produção de alimentos ou de biomassa para a produção de energia ocorre por mudança no uso da terra, marcadamente das áreas de pastagens de baixa produtividade no Cerrado. Essa alternativa de uso mais eficiente da terra é reforçada pelo baixo retorno econômico da pecuária extensiva e da extensa área de pastagens em degradação (Martha Junior et al., 2007). Assim, a oferta de produtos agrícolas e de bioenergia aumentaria, sem promover novos desmatamentos, e áreas de pecuária de baixa produtividade ou degradadas seriam recuperadas por meio de atividades agrícolas mais eficientes, como lavouras de grãos, cana-de-açúcar ou pecuária produtiva (Martha Junior, 2008).

\section{Desafios e perspectivas}

Apesar dos potenciais benefícios da integração lavoura-pecuária, a adoção desses sistemas mistos de produção ainda é relativamente pequena no Brasil, cerca de 1,5 milhão de hectares (Balbino et al., 2011). Migrar de sistemas especializados para sistemas mistos, mais complexos, demanda maior capacidade gerencial, equipes especializadas e mais investimentos em infraestrutura. Além disso, na falta de recursos adequados para investimento e custeio (volume e prazos), os incentivos para promover a intensificação do uso de áreas agrícolas podem ser de baixa eficácia.

A expectativa é de que a adoção de integração lavoura-pecuária pelos produtores resulte em melhorias significativas na sustentabilidade socioeconômica e ambiental de suas propriedades e da região de influência de suas fazendas. Portanto, concentrar esforços nos fatores que limitam a adoção desse sistema no Cerrado parece ser o ponto estratégico dos novos estudos. Há evidências de que a melhoria na qualidade de cobertura de solo para o sistema de plantio direto, por meio de gramíneas forrageiras, pode auxiliar no aumento da adoção da integração lavoura-pecuária no Cerrado.

No Cerrado, entre as braquiárias, a U. ruziziensis tem assumido importância crescente quando o foco é o plantio direto. Essa espécie, até o início da década de 2000, não tinha expressão no comércio de sementes de forrageiras no Brasil. Contudo, segundo a Associação para o Fomento à Pesquisa de Melhoramento de Forrageiras Tropicais (2011), entre 2007 e 2010, a área de produção de sementes dessa espécie passou de 2.412 ha para 11.582 ha, o que representa uma taxa de aumento de $68,7 \%$ ao ano. Esse aumento expressivo de área para produção é explicado pela grande demanda de sementes pelos produtores para o plantio em consórcio com cultivos, sobretudo, com milho.

Embora esse consórcio seja utilizado principalmente como cobertura de solo para o sistema plantio direto, na primeira safra de verão e na segunda safra (safrinha), os produtores têm ampliado suas áreas com esse consórcio, em virtude dos benefícios para a produtividade das culturas em sucessão à braquiária. A expressiva massa de forragem obtida nesse sistema (em torno de $20 \mathrm{Mg}$ ha $^{-1}$ de massa verde) tem despertado o interesse dos produtores em aproveitar essa forragem na alimentação animal.

Cobucci et al. (2007), em estudos realizados em Mato Grosso e Maranhão, confirmaram o potencial do sistema de integração lavoura-pecuária para produção de carne, na entressafra (maio a setembro). Os ganhos obtidos variaram de 67,5 a $127,5 \mathrm{~kg} \mathrm{ha}^{-1}$ de equivalente de carcaça, o que ratifica o potencial da engorda de boi na entressafra ("safrinha de boi"), na integração lavoura-pecuária, em fazendas com foco na produção de grãos.

A integração lavoura-pecuária é um sistema que, em príncipio, adapta-se a qualquer tamanho de propriedade, desde que as condições edafoclimáticas não sejam restritivas. Contudo, em propriedades caracterizadas pelo uso intensivo de máquinas agrícolas e insumos (corretivos, fertilizantes, herbicidas e pesticidas), a escala de produção pode ser determinante da viabilidade econômica do sistema. É necessário planejamento eficiente, gestão competente e envolvimento de equipe multidisciplinar (multicompetências). 
Os sistemas mistos, como a integração lavoura-pecuária, são, em geral, mais sustentáveis do que os sistemas especializados (monocultivos) e podem auxiliar no atendimento da demanda crescente por alimentos, fibras e bioenergia, sem comprometer a sustentabilidade dos ecossistemas e dos agroecossistemas do Cerrado. Entretanto, ainda existem lacunas de conhecimento para o aprimoramento e o desenvolvimento desses sistemas de produção, para torná-los mais eficientes no uso dos recursos naturais.

Pesquisas em integração lavoura-pecuária tem recebido a atenção de várias instituições. A maioria dos estudos tem focado no consórcio de forrageiras com culturas de grãos e na melhoria das propriedades químicas, fisicas e biológicas do solo. Alguns trabalhos sobre o efeito da braquiária no ciclo de pragas e doenças também tem sido realizados. No entanto, são necessárias mais informações sobre a redução de uso de defensivos agrícolas e a quebra de ciclo de endo e ectoparasistas em animais em pastejo. Outro tema que merece atenção é o efeito do pastejo na ciclagem de nutrientes, nos sistemas de integração lavoura-pecuária.

Estudos sobre a introdução do componente arbóreo nesse sistema também devem ser incentivados e ampliados. Para maximizar a produtividade dos componentes (agrícola, animal e florestal), futuros trabalhos devem focar na diversificação de espécies arbóreas - nativas e exóticas - e forrageiras, na densidade de árvores, na ciclagem de nutrientes e na ambiência animal. De acordo com Macedo et al. (2010), as inúmeras possibilidades de combinações de espécies, cultivares e clones e de arranjos estruturais determinam interações entre os componentes e o manejo que necessitam ser melhor compreendidas para estabelecer sistemas agrossilvipastoris mais produtivos e adaptados às diferentes regiões do Brasil.

\section{Agradecimentos}

À Financiadora de Estudos e Projetos, ao Conselho Nacional de Desenvolvimento Científico e Tecnológico, à Embrapa e à Bunge, pelo apoio financeiro.

\section{Referências}

ALVARENGA, C.R.; GONTIJO NETO, M.M.; RAMALHO, J.H.; GARCIA, J.C.; VIANA, M.C.M.; CASTRO, A.A.D.N. Sistema de integração lavoura-pecuária: o modelo implantado na Embrapa Milho e Sorgo. Sete Lagoas: Embrapa Milho e Sorgo, 2007. 9P. (Embrapa Milho e Sorgo. Circular técnica, 93).
ASSOCIAÇÃO PARA O FOMENTO À PESQUISA DE MELHORAMENTO DE FORRAGEIRAS TROPICAIS. Associação para o Fomento à Pesquisa de Melhoramento de Forrageiras Tropicais [home page]. Disponível em: $<$ http://www. unipasto.com.br/>. Acesso em: 26 out. 2011.

AYARZA, M.A.; VILELA, L.; PIZARRO, E.A.; COSTA, P.H. da. Agropastoral systems based on legumes: an alternative for sustainable agriculture in the Brazilian Cerrados. In: THOMAS, R.E.; AYARZA, M.A. (Ed.). Sustainable land management for the oxisols of the Latin American savannas. Cali: CIAT, 1999. p.22-36. (Publicación CIAT, 312).

BALBINO, L.C.; BARCELlOS, A. de O.; STONE, L.F. Marco referencial: integração lavoura-pecuária-floresta (iLPF). Brasília: Embrapa, 2011. 130p.

BARCELLOS, A. de O.; VIANNA FILHO, A.; BALBINO, L.C.; OLIVEIRA, I.P. de; YOKOYAMA, L.P. Restabelecimento da capacidade produtiva e desempenho animal em pastagens renovadas na região do Cerrado. Planaltina: Embrapa Cerrados, 1999. 4P. (Embrapa Cerrados. Comunicado técnico, 22).

CASSOL, L.C. Relações solo-planta-animal num sistema de integração lavoura-pecuária em semeadura direta com calcário na superfície. 2003. 143P. Tese (Doutorado) - Universidade Federal do Rio Grande do Sul, Porto Alegre.

CASTRO FILHO, C.; HENKLAIN, J.C.; VIEIRA, M.J.; CASÃO JÚNIOR, R. Tillage methods and soil and water conservation in southern Brazil. Soil and Tillage Research, v.20, p.271-283, 1991.

COBUCCI, T.; PORTELA, C.M.O. Manejo de herbicidas no Sistema Santa Fé e na braquiária como fonte de cobertura morta. In: KLUTHCOUSKI, J.; STONE, L.F.; AIDAR, H. (Ed.). Integração lavoura-pecuária. Santo Antônio de Goiás: Embrapa Arroz e Feijão, 2003. p.443-458.

COBUCCI, T.; WRUCK, F.J.; KLUTHCOUSKI, J.; MUNIZ, L.C.; MARTHA JUNIOR, G.B.; CARNEVALLI, R.A.; TEIXEIRA, S.R.; MACHADO, A.A.; TEIXEIRA NETO, M.L. Opções de integração lavoura-pecuária e alguns de seus aspectos econômicos. Informe Agropecuário, v.28, p.64-79, 2007.

CORSI, M.; MARTHA JUNIOR, G.B.; PAGOTTO, D.S. Sistema radicular: dinâmica e resposta a regimes de desfolha. In: DA SILVA, S.C.; PEDREIRA, C.G.S. (Ed.). A produção animal na visão dos brasileiros - pastagens. Piracicaba: FEALQ, 2001. p.838-852.

COSTA, J.L. da S.; RAVA, C.A. Influência da braquiária no manejo de doenças do feijoeiro com origem no solo. In: KLUTHCOUSKI, J.; STONE, L.F.; AIDAR, H. (Ed.). Integração lavoura-pecuária. Santo Antônio de Goiás: Embrapa Arroz e Feijão, 2003. p.523-533.

DECAËNS, T.; BUREAU, F.; MARGERIE, P. Earthworm communities in a wet agricultural landscape of the Seine Valley (Upper Normandy, France). Pedobiologia, v.47, p.479-489, 2003.

DEDECEK, R.A.; RESCK, D.V.S.; FREITAS JUNIOR, E. de. Perdas de solo, água e nutrientes por erosão em Latossolo Vermelho-Escuro dos cerrados em diferentes cultivos sob chuva natural. Revista Brasileira de Ciência do Solo, v.10, p.265-272, 1986.

DERAMUS, H.A.; CLEMENT, T.C.; GIAMPOLA, D.D.; DICKISON, P.C. Methane emissions of beef cattle on forages: 
efficiency of grazing management systems. Journal of Environmental Quality, v.32, p.269-277, 2003.

FEIGL, B.J.; BERNOUX, M.; CERRI, C.C.; PICCOLO, M.C. $\mathrm{O}$ efeito da sucessão floresta/pastagem sobre o estoque de carbono e o fluxo de gases em solos da Amazônia. In: LIMA, M.A. de; RODRIGUES, O.M.; GONZALEZ MIGUEZ, J.D. (Ed.). Mudanças climáticas globais e a agropecuária brasileira. Jaguariúna: Embrapa Meio Ambiente, 2001. p.257-271.

FOX, R.H.; SEARLE, P.G.E. Phosphate adsorption by soils of the tropics. In: DROSDOFF, M.; DANIELS, R.B.; NICHOLAIDES III, J.J. (Ed.). Diversity of soils in the tropics. Madison: American Society of Agronomy, 1978. p.97-119. (ASA. Special publication, 34).

FRANZLUEBBERS, A.J. Integrated crop-livestock systems in the southeastern USA. Agronomy Journal, v.99, p.361-372, 2007.

FREITAS, F.C.L.; FERREIRA, L.R.; FERREIRA, F.A.; SANTOS, M.V.; AGNES, E.L.;CARDOSO, A.A.; JAKELAITIS, A. Formação de pastagem via consórcio de Brachiaria brizantha com o milho para silagem no sistema de plantio direto. Planta Daninha, v.23, p.49-58, 2005.

GARCÍA-PRÉCHAC, F.; ERNST, O.; SIRI-PRIETO, G.; TERRA, J.A. Integrating no-till into crop-pasture rotations in Uruguay. Soil and Tillage Research, v.77, p.1-13, 2004.

GÖRGEN, C.A.; CIVARDI, E.A; RAGAGNIM, V.A.; SILVEIRA NETO, A.N. da.; CARNEIRO, L.C.; LOBO JUNIOR, M. Redução do inóculo inicial de Sclerotinia sclerotiorum em soja cultivada após uso do sistema Santa Fé. Pesquisa Agropecuária Brasileira, v.45, p.1102-1108, 2010.

GREENWOOD, K.L.; MCKENZIE, B.M. Grazing effects on soil physical properties and the consequences for pastures: a review. Australian Journal of Experimental Agriculture, v.41, p.1231-1250, 2001.

GUO, L.B.; GIFFORD, R.M. Soil carbon stocks and land use change: a meta analysis. Global Change Biology, v.8, p.345-360, 2002.

IKEDA, F.S.; MITJIA, D.; VILELA, L.; CARMONA, R. Banco de sementes no solo em sistemas de cultivo lavoura-pastagem. Pesquisa Agropecuária Brasileira, v.42, p.1545-1551, 2007.

INOMOTO, M.M.; MACHADO, A.C.Z.; ANTEDOMÊNICO, S.R. Reação de Brachiaria spP. e Panicum maximum a Pratylenchus brachyurus. Fitopatologia Brasileira, v.32, p.341-344, 2007.

JAKELAITIS, A.; SILVA, A.A.; FERREIRA, L.R.; SILVA, A.F.; FREITAS, F.C.L. Manejo de plantas daninhas no consórcio de milho com capim-braquiária (Brachiaria decumbens). Planta Daninha, v.22, p.553-560, 2004.

JAKELAITIS, A.; SILVA, A.F.; SILVA, A.A.; FERREIRA, L.R.; VIVIAN, R. Influência de herbicidas e de sistemas de semeadura de Brachiaria brizantha consorciada com milho. Planta Daninha, v.23, p.59-67, 2005.

KLUTHCOUSKI, J.; AIDAR, H. Implantação, condução e resultados obtidos com o Sistema Santa Fé. In: KLUTHCOUSKI, J.; STONE, L.F.; AIDAR, H. (Ed.). Integração lavoura-pecuária. Santo Antônio de Goiás: Embrapa Arroz e Feijão, 2003. p.407-442.

LAL, R. Tillage and agricultural sustainability. Soil and Tillage Research, v.20, p.133-146, 1991.
LANZANOVA, M.E.; NICOLOSO, R. da S.; LOVATO, T.; ELTZ, F.L.F.; AMADO, T.J.C.; REINERT, D.J. Atributos físicos do solo em sistema de integração lavoura-pecuária sob plantio direto. Revista Brasileira de Ciência do Solo, v.31, p.1131-1140, 2007.

LAZZAROTTO, J.J.; SANTOS, M.L. dos; LIMA, J.E. de; MORAES, A. de. Volatilidade dos retornos econômicos associados à integração lavoura-pecuária no Estado do Paraná. Revista de Economia e Agronegócio, v.7, p.259-283, 2009.

LIMA, J.E.F.W.; SILVA, E.M. da. Recursos hídricos do bioma Cerrado. In: SANO, S.M.; ALMEIDA, S.P. de; RIBEIRO, J.F. (Ed.). Cerrado: ecologia e flora. 2.ed. Planaltina: Embrapa Cerrados; Brasília: Embrapa Informação Tecnológica, 2008. v.1, p.89-106.

LIMA, M.A. de. Agropecuária brasileira e as mudanças climáticas globais: caracterização do problema, oportunidades e desafios. Cadernos de Ciência e Tecnologia, v.19, p.451-472, 2002.

LYNCH, J.M.; BRAGG, E. Microorganisms and soil aggregate stability. Advances in Soil Science, v.2, p.133-171, 1985.

MACEDO, M.C.M. Integração lavoura-pecuária: o estado da arte e inovações tecnológicas. Revista Brasileira de Zootecnia, v.28, p.133-146, 2009.

MACEDO, M.C.M. Sustainability of pasture production in the savannas of tropicalAmerica. In: INTERNATIONAL GRASSLAND CONFERENCE, 18., 1997, Winnipeg and Saskatoon. Proceedings. [S.I.]: Canadian Society of Agronomy: Canadian Society of Animal Science, 1997. v.4, p.391-399.

MACEDO, R.L.G.; VALE, A.B. do; VENTURIN, N. Eucalipto em sistemas agroflorestais. Lavras: UFLA, 2010. 331p.

MACHADO, L.A.Z.; ASSIS, P.G.G. de. Produção de palha e forragem por espécies anuais e perenes em sucessão à soja. Pesquisa Agropecuária Brasileira, v.45, p.415-422, 2010.

MACHADO, L.A.Z.; CECCON, G. Sistemas integrados de agricultura e pecuária. In: PIRES, A.V. (Ed.). Bovinocultura de corte. Piracicaba: FEALQ, 2010. v.2, p.1401-1462.

MARCHÃO, R.L.; BALBINO, L.C.; SILVA, E.M. da; SANTOS JUNIOR, J. de D.G. dos; SÁ, M.A.C.; VILELA, L.; BECQUER, T. Qualidade física de um Latossolo Vermelho sob sistemas de integração lavoura-pecuária no Cerrado. Pesquisa Agropecuária Brasileira, v.42, p.873-882, 2007.

MARCHÃO, R.L.; LAVELLE, P.; CELINE, L.; BALBINO, L.C.; VILELA, L.; BECQUER, T. Soil macrofauna under integrated crop-livestock systems in a Brazilian Cerrado Ferralsol. Pesquisa Agropecuária Brasileira, v.44, p.1011-1020, 2009.

MARTHA JUNIOR, G.B. Dinâmica de uso da terra em resposta à expansão da cana-de-açúcar no Cerrado. Revista de Política Agrícola, v.17, p.31-43, 2008.

MARTHA JUNIOR, G.B.; VILELA, L.; BARCELLOS, A. de O. A planta forrageira e o agroecossistema. In: SIMPÓSIO SOBRE O MANEJO DA PASTAGEM, 23., 2006, Piracicaba. As pastagens e o meio ambiente: anais. Piracicaba: FEALQ, 2006. p.87-138.

MARTHA JUNIOR, G.B.; VILELA, L.; SOUSA, D.M.G. de. Integração lavoura-pecuária. In: PROCHNOW, L.I.; CASARIN, V.; STIPP, S.R. (Ed.). Boas práticas para uso eficiente de fertilizantes. Piracicaba: IPNI, 2010. v.3, p.287-307. 
MARTHA JUNIOR, G.B.; VILELA, L.; SOUSA, D.M.G. de (Ed.). Cerrado: uso eficiente de corretivos e fertilizantes em pastagens. Planaltina: Embrapa Cerrados, 2007. 224p.

MIRANDA, J.C.C. de; VILELA, L.; MIRANDA, L.N. de. Dinâmica e contribuição da micorriza arbuscular em sistemas de produção com rotação de culturas. Pesquisa Agropecuária Brasileira, v.40, p.1005-1014, 2005.

MORAES, A. de; CARVALHO, P.C. de F.; PELISSARI, A.; ALVES, S.J.; LANG, C.R. Sistemas de integração lavoura-pecuária no subtrópico da América do Sul: exemplos do Sul do Brasil. In: SIMPÓSIO INTERNACIONAL EM INTEGRAÇÃO LAVOURA-PECUÁRIA, 2007, Curitiba. [Anais]. Curitiba: UFPR, 2007. 27p. CD-ROM.

PORTES, T. de A.; CARVALHO, S.I.C. de; OLIVEIRA, I.P. de; KLUTHCOUSKI, J. Análise do crescimento de uma cultivar de braquiária em cultivo solteiro e consorciado com cereais. Pesquisa Agropecuária Brasileira, v.35, p.1349-1358, 2000.

SALTON, J. Matéria orgânica e agregação do solo na rotação lavoura-pastagem em ambiente tropical. 2005. 155P. Tese (Doutorado) - Universidade Federal do Rio Grande do Sul, Porto Alegre.

SEVERINO, F.J.; CARVALHO, S.J.P.; CHRISTOFFOLETI, P.J. Interferências mútuas entre a cultura do milho, espécies forrageiras e plantas daninhas em um sistema de consórcio. III - Implicações sobre as plantas daninhas. Planta Daninha, v.24, p.53-60, 2006.

SILVA, A.C.; FERREIRA, L.R.; SILVA, A.A. da; FREITAS, R.S.; MAURO, A. Épocas de emergência de Brachiaria brizantha no desenvolvimento da cultura da soja. Ciência Rural, v.35, p.769-775, 2005.

SILVA, A.C.; FERREIRA, L.R.; SILVA, A.A. da; PAIVA, T.W.B.; SEDIYAMA, C.S. Efeito de doses reduzidas de fluazifop-p-butil no consórcio entre soja e Brachiaria brizantha. Planta Daninha, v.22, p.429-435, 2004.

SILVA, A.C. da; FREITAS, F.C.; FERREIRA, L.R.; FREITAS, R.S. Dessecação pré-colheita de soja e Brachiaria brizantha consorciadas com doses reduzidas de graminicida. Pesquisa Agropecuária Brasileira, v.41, p.37-42, 2006.

SOUSA, D.G.M. de; LOBATO, E. Correção da acidez do solo. In: SOUSA, D.G.M. de; LOBATO, E. (Ed.). Cerrado: correção do solo e adubação. 2.ed. Brasília: Embrapa Informação Tecnológica; Planaltina: Embrapa Cerrados, 2004. p.81-96.

SOUSA, D.M.G. de; MARTHA JUNIOR, G.B.; VILELA, L. Adubação fosfatada. In: MARTHA JUNIOR, G.B. de; VILELA, L.;
SOUSA, D.M.G. de. Cerrado: uso eficiente de corretivos e fertilizantes em pastagens. Planaltina: Embrapa Cerrados, 2007. p.145-177.

SOUSA, D.M.G. de; REIN, T.A.; GOEDERT, W.J.; NUNES, R. de S. Fósforo. In: PROCHNOW, L.I.; CASARIN, V.; STIPP, S.R. (Ed.). Boas práticas para uso eficiente de fertilizantes. Piracicaba: IPNI, 2010. v.2, p.67-134.

SPAIN, J.M.; AYARZA, M.A.; VILELA, L. Crop pasture rotations in the Brazilian cerrados. In: INTERNATIONAL SYMPOSIUM ON TROPICAL SAVANNAS, 1., 1996, Brasilia, DF. Biodiversidade e produção sustentável de alimentos e fibras nos cerrados: Anais. Planaltina: Embrapa-CPAC, 1996. p.39-45.

STUDDERT, G.A.; ECHEVERRÍA, H.E.; CASANOVAS, E.M. Crop-pasture rotation for sustaining the quality and productivity of a typic argiudoll. Soil Science Society of American Journal, v.61, p.1466-1472, 1997.

THUROW, T.L. Hydrology and erosion. In: HEITSCHMIDT, R.K.; STUTH, J.W. (Ed.). Grazing management: an ecological perspective. Portland: Timber, 1991. p.141-159.

UNITED STATES ENVIRONMENTAL PROTECTION AGENCY. Anthropogenic methane emissions in the United States: estimates for 1990: report to congress. Washington: EPA, 1993. 254p.

VILELA, L.; BARCELLOS, A. de O.; MARTHA JUNIOR, G.B. Plantio direto de pastagens. In: SIMPÓSIO SOBRE MANEJO DA PASTAGEM, 23., 2006, Piracicaba. As pastagens e o meio ambiente: anais. Piracicaba: FEALQ, 2006. p.165-185.

VILELA, L.; MACEDO, M.C.M.; MARTHA JUNIOR, G.B.; KLUTHCOUSKI, J. Benefícios da integração lavoura-pecuária. In: KLUTHCOUSKI, J.; STONE, L.F.; AIDAR, H. (Ed.). Integração lavoura-pecuária. Santo Antônio de Goiás: Embrapa Arroz e Feijão, 2003. p.143-170.

VILELA, L.; MARTHA JUNIOR, G.B.; MARCHÃO, R.L.; GUIMARÃES JUNIOR, R.; BARIONI, L.G.; BARCELLOS, A. de O. Integração lavoura-pecuária. In:FALEIRO, F.G.; FARIAS NETO, A.L. de (Ed.). Savanas: desafios e estratégias para o equilíbrio entre sociedade, agronegócio e recursos naturais. Planaltina: Embrapa Cerrados, 2008. p.933-962.

WILKINS, R.J. Eco-efficient approaches to land management: a case for increased integration of crop and animal production systems. Philosophical Transactions of the Royal Society B Biological Sciences, v.363, p.517-525, 2008.

Recebido em 15 de abril de 2011 e aprovado em 7 de outubro de 2011 